\title{
Severe Acute Respiratory Syndrome Coronavirus-2 (SARS-CoV-2): An Emerging Zoonotic Respiratory Pathogen in Humans
}

\author{
Ashwini Malla\# (D), Balamurugan Shanmugaraj" (D) and \\ Sathishkumar Ramalingam* (D) \\ Plant Genetic Engineering Laboratory, Department of Biotechnology, Bharathiar University, \\ Coimbatore - 641 046, Tamil Nadu, India.
}

\begin{abstract}
Two highly human pathogenic coronaviruses outbreak in the beginning of $21^{\text {st }}$ century i.e. Severe Acute Respiratory Syndrome Coronavirus (SARS-CoV) and Middle East Respiratory Syndrome Coronavirus (MERS-CoV) in 2002 and 2012 respectively caused high pathogenicity and fatality rates in human populations. Recently, a new coronavirus named as SARS-CoV-2 or nCoV-2019 was first reported in Wuhan, China in December 2019 which is responsible for an acute human respiratory illness referred as Coronavirus Disease (COVID-19), an ongoing pandemic. SARS-CoV-2 is the third known highly pathogenic virus affecting human population. This virus spread globally within few weeks of first identification and nearly $\mathbf{5 . 5 2}$ million confirmed cases with more than $\mathbf{3 , 4 7 , 0 0 0}$ deaths reported as of May 25, 2020. Till date, there are no specific anti-viral drugs, therapies or vaccines to contain and prevent this infectious pathogen outbreak. The global spread of this virus to over $\mathbf{2 1 0}$ countries resulted in both human and economic losses, highlighting the need for an immediate imperative research exploration on prophylactic and therapeutic measures. Current knowledge and understanding of the pathogenesis of similar coronavirus SARS-CoV and MERS-CoV might be helpful for the rapid development of treatment strategies to prevent the further spread of this virus. In this review, we recapitulate the topical understanding on the structure, pathogenesis and epidemiology of SARS-CoV-2 that has emerged as a major health concern worldwide.
\end{abstract}

Keywords: Coronavirus, COVID-19, Epidemiology, MERS-CoV, SARS-CoV, SARS-CoV-2

*Correspondence: rsathish@buc.edu.in; +919360151669; "Both the authors contributed equally.

(Received: May 03, 2020; accepted: May 25 2020)

Citation: Malla A, Shanmugaraj B, Ramalingam S. Severe Acute Respiratory Syndrome Coronavirus-2 (SARS-CoV-2): An Emerging Zoonotic Respiratory Pathogen in Humans. J Pure Appl Microbiol. 2020;14(suppl 1):931-936. doi: 10.22207/JPAM.14.SPL1.30

(C) The Author(s) 2020. Open Access. This article is distributed under the terms of the Creative Commons Attribution 4.0 International License which permits unrestricted use, sharing, distribution, and reproduction in any medium, provided you give appropriate credit to the original author(s) and the source, provide a link to the Creative Commons license, and indicate if changes were made. 


\section{INTRODUCTION}

The epidemic outbreak of Chikungunya, Zika, Ebola, Nipah, SARS, MERS in $21^{\text {st }}$ century threatens the global health security by causing devastating pathogenic infections with high fatality in human population ${ }^{1,2}$. The recent emergence of 2019 novel coronavirus, SARS-CoV- 2 is responsible for severe respiratory illness termed as Coronavirus Disease (COVID-19). The virus was first reported to be originated in Wuhan, Hebei Province, China, that rapidly spread globaly with cases reported in 6 continents claiming almost $>3,47,000$ lives since its emergence in December, 2019. World Health Organization (WHO) has announced the COVID-19 outbreak as Public Health Emergency of International Concern (PHEIC) on $30^{\text {th }}$ January $2020^{3}$.

Coronavirus is an enveloped, spherical virus which belongs to the order Nidovirales, family Coronaviridae and subfamily Coronavirinae ${ }^{4}$. It contains non-segmented positive sense single stranded RNA measuring about $120 \mathrm{~nm}$ in diameter. The nucleocapsid that is formed with association of nucleoprotein and RNA genome is arranged in helical symmetry. The coronaviruses have the largest RNA genome with a size of $27-32 \mathrm{~kb}^{5}$ flanked with $5^{\prime}$ cap and $3^{\prime}$ polyadenylated tail. Coronaviruses are zoonotic in nature infecting wide variety of vertebrates. The subfamily Coronavirinae is further classified into four genera: Alphacoronavirus, Betacoronavirus, Gammacoronavirus, and Deltacoronavirus. Among the four genera, two genera Gammacoronaviruses, Deltacoronaviruses have been found to infect livestock, birds, bats, whales, mice and other wild animals, while the other two genera Alphacoronaviruses and Betacoronaviruses can infect mammals.

In addition to SARS-CoV, MERS-CoV and SARS-CoV-2, there are four other coronaviruses (OC43, 229E, NL63 and HKU1) known to infect humans. The coronaviruses majorly cause respiratory disorders with a variable degree of severity ranging from mild to severe respiratory syndrome across all age groups ${ }^{7}$. The pathogenesis of this virus is still not yet elucidated completely; however, similar mechanisms may underlie in the pathogenesis of both SARS and SARS-CoV-2. In this review, the current knowledge on epidemiology and clinical features of COVID-19 are discussed.

\section{Genome Organization}

The basic genome organization of coronavirus comprises of four structural proteins viz., spike glycoprotein (S), nucleoprotein $(\mathrm{N})$, envelope protein (E) and membrane protein (M). Few coronaviruses from other groups also encode for another protein called haemagglutinin esterase (HE) that aids in viral entry playing a crucial role during the infection in natural host ${ }^{8}$. S proteins have a size of $\sim 150 \mathrm{kDa}$ and are heavily glycosylated ${ }^{9}$. They are present on the outer surface and generally form homotrimers giving the crown or halo like morphology to the virus; hence the name Coronavirus ${ }^{10}$. These proteins interact with the $M$ proteins by binding to the membrane of virion at the C-terminal in the transmembrane domain ${ }^{11}$. The $\mathrm{N}$-terminal region of $\mathrm{S}$ protein helps in the attachment of virion to the surface specific receptors of host cell plasma membrane ${ }^{12}$. The host cell proteases cleave the spike protein into 2 polypeptides such as $\mathrm{S} 1$ and S2, where S1 acts as the large receptor binding domain and S2 as the spike stalk ${ }^{13}$. M protein has three transmembrane regions and undergoes glycosylation in golgi apparatus which attributes for the antigenicity of its protein ${ }^{14}$. Apart from its key role of regenerating the virions in the host cell, it also induces the propagation of active virions in Endoplasmic reticulum-Golgi apparatus intermediate compartment (ERGIC) and N proteingenomic RNA complex ${ }^{15}$.

E proteins are tiny integral proteins consisting of 76-109 amino acids. They are responsible for virus assembly, morphogenesis and budding in the host cell. E proteins also play a crucial part in the viral release where the release can be inhibited completely or partially in their absence ${ }^{16}$. They exhibit ion channel activity essential for optimal virus replication. ${ }^{17} \mathrm{~N}$ protein has a structural role and is vital for viral RNA encapsidation. It also acts as an interferon antagonist, upregulates a kind of prothrombinase that causes fatal hepatic disease ${ }^{18}$. The length of $\mathrm{N}$ protein may vary in different coronaviruses, but some of $\mathrm{N}$-protein motifs are conserved with a three-domain organization ${ }^{19}$.

The recent studies on full length genomic sequencing and phylogenetic analysis revealed that SARS-CoV-2 belongs to Betacoronavirus sharing the same sub-genus as that of SARS- 
CoV responsible for SARS outbreak in the year 2002-20037. SARS-CoV-2 was reported to use angiotensin-converting enzyme 2 (ACE2) surface receptor on the host cell for its entry, revealing the structural similarity with SARS-CoV receptor binding domain ${ }^{20}$. The genomic RNA undergoes translation to express the coronavirus replicasetranscriptase protein genes. The open reading frame (ORF) 1a and ORF $1 \mathrm{~b}$ encodes the replicasetranscriptase proteins, for synthesis of two large polyproteins namely, pp1a and pp1ab. During the translation of ORF1a, a programmed ribosomal frame shift occurs in the synthesis of pp1ab polyprotein ${ }^{7,21}$. The viral proteases such as chymotrypsin-like or papain-like proteases further process these polypeptides to 16 non-structural protein $s^{22}$. The $S$ protein aids in the attachment of the virus to host receptors via., endocytosis for cell entry ${ }^{13}$. The fusion of virus with host endosomal membrane occurs and the ssRNA is then released into the cytoplasm ${ }^{23}$. Viral factories start the replication after proteolytic cleavages synthesizing the copies of genomic RNA. The structural proteins are expressed as sub-genomic RNA using the replication transcription complex by discontinuous transcription ${ }^{24}$. Assembly or budding of the virus occurs in ERGIC and the new virions are released by exocytosis ${ }^{23}$. Epidemiology

The recently evolved SARS-CoV-2 was first reported in Wuhan, Hebei province, China in December, 2019. Later in January 2020, cases have been reported outside Wuhan city indicating human to human transmission ${ }^{25}$. The number of infected cases rapidly increased in China and other countries, with the first case outside China being reported in Thailand who was a female tourist from Wuhan ${ }^{26}$. Similar like SARS-CoV-2, SARS-CoV was originated in China in November 2002, spreading rapidly in the Asian countries with a total number of cases nearing 8500 and 1000 deaths globally as of June, $2003^{27}$. Middle East respiratory syndrome (MERS) epidemics began during 2012, with almost more than 2200 confirmed cases reported from 27 countries all over the world with the Middle East being the epicentre until $2018^{28}$.

The local outbreak in Wuhan at the seafood wholesale wet market marked the beginning of phase I COVID-19, confirming 41 cases by mid of January, 2020. Since then, the phase II began reporting the rapid expansion and spread of COVID-19 in the hospitals along with close contact transmission with nearly 900 cases showing almost 20-fold increase in the third week of January, 2020. Clusters of confirmed COVID-19 with > than 9500 cases were reported in the last week of January, 2020, moving to the third phase where the outbreak was stated as $\mathrm{PHEIC}$ by $\mathrm{WHO}^{26}$. Globally, there are about 5.52 million affected cases and 3,47,000 deaths reported as of May 25, 2020. More number of infected cases were reported in USA, European countries including Spain, Italy, the Great Britain, Germany, and France with $>1,50,000$ cases and high fatality rate. Several states in USA are hit badly with $>10,50,000$ cases and nearly 57,400 deaths indicating community transmission. The epicenter China reported a total number of about 84300 cases, with the recent ones identified as imported cases after revoking its lockdown measures in early April, $2020^{29}$.

Symptoms and Transmission

The incubation period of virus ranges from 2-14 days and the symptoms may occur within 2 weeks after exposure. Reported illnesses and confirmed cases have shown the symptoms of fever, cough, myalgia or fatigue and shortness of breath. However respiratory failure, septic shock and multi-organ failure are also reported. Severe illness cases showed dyspnea, hypoxemia and infiltrates of viruses in pulmonary region of infected person ${ }^{30,31}$.

Bats are considered as prime host and reservoir for coronaviruses. Although the source of the SARS-CoV-2 is still in a debate, bats are believed to be the virus reservoir. Primary cases of COVID-19 were reported from the individuals linked with Huanan seafood market, China. The main route of transmission for all three human pathogenic coronaviruses SARS, MERS and COVID-19 are confirmed to be spread mainly from human to human and reported to occur via., the respiratory droplets generated from an infected person's cough or sneeze. The droplets produced from an infected person can directly contact the surrounding or nearby population causing the transmission of infection. Nosocomial transmission linked with infected patients to healthcare workers in hospitals should be analysed to identify the modes of virus spread ${ }^{32}$. It is still unclear and many more features of the COVID-19 needs to 
be unravelled for the complete understanding of its virus transmission cycles, and spread of the disease ${ }^{33}$.

Prevention and Treatment

Currently there are no vaccines or antiviral therapies to prevent the coronaviruses including COVID-19. The best way to prevent the virus infection right now is to stay away from the infected people and follow simple personal hygienic precautions i.e., washing hands frequently with sanitizers, avoiding the touch of sensory organs with unwashed hands, wearing a respiratory mask and personal protective equipment are few precautionary measures suggested by WHO, that can aid in controlling the spread of the disease. The coronavirus infections can be controlled by identifying the source of infection, preliminary diagnosis, keeping infected people isolated with supportive treatment and care for vital organ functioning ${ }^{33}$. Quarantine and other public health measures can also be implemented to control the movement of people during an epidemic outbreak. After the epidemics of highly pathogenic SARS-CoV and MERS-CoV, several antiviral agents against coronaviruses have been developed and are in clinical trials. The current research has been focused on identifying an effective anti-viral drug or antibody molecule targeting the conserved region of the virus spike protein as it plays an important role in virus entry, and their potential in eliciting the host immune responses in infected individuals. The potential Table 1. Status of few candidate vaccines for COVID-19 under Development (Modified from WHO, 2020 ${ }^{35}$ )

\begin{tabular}{|c|c|c|}
\hline \multirow{3}{*}{$\begin{array}{l}\text { Development Platform } \\
\text { Non-Replicating Viral Vector }\end{array}$} & \multicolumn{2}{|l|}{ Vaccines in Phase I Clinical Trials } \\
\hline & Type of Vaccine Candidate & Developer \\
\hline & Adenovirus Type 5 Vector (Ad5-nCoV) & $\begin{array}{l}\text { CanSino Biological Inc. and Beijing } \\
\text { Institute of Biotechnology }\end{array}$ \\
\hline \multirow[t]{2}{*}{ RNA } & LNP encapsulated mRNA (mRNA-1273) & Moderna/NIAID \\
\hline & \multicolumn{2}{|l|}{ Vaccines in Preclinical Studies } \\
\hline DNA & $\begin{array}{l}\text { DNA plasmid vaccine Electroporation } \\
\text { device (INO-4800) }\end{array}$ & Inovio Pharmaceuticals \\
\hline Inactivated & Formaldehyde inactivated + alum & Sinovac \\
\hline Live Attenuated Virus & Codon Deoptimized live attenuated vaccines & Codagenix/Serum Institute of India \\
\hline \multirow[t]{7}{*}{ Non-Replicating Viral Vector } & MVA encoded VLP & GeoVax/BravoVax \\
\hline & Ad26 (alone or with MVA boost) & Janssen Pharmaceutical Companies \\
\hline & ChAdOx1 & University of Oxford \\
\hline & Adenovirus based NasoVAX expressing & \\
\hline & SARS2-CoV spike protein & Altimmune \\
\hline & Ad5 S (GREVAX ${ }^{\mathrm{TM}}$ platform) & Greffex \\
\hline & Oral Vaccine platform & Vaxart \\
\hline \multirow[t]{8}{*}{ Protein Subunit } & COVID-19 S-Trimer & Clover Biopharmaceuticals Inc./GSK \\
\hline & li-Key peptide & Generex/EpiVax \\
\hline & S protein & EpiVax/Univ. of Georgia \\
\hline & S protein (Baculovirus production) & Sanofi Pasteur \\
\hline & \multicolumn{2}{|c|}{ Full length S trimers/ nanoparticle + Matrix M (NVX-CoV2373) } \\
\hline & gp-96 backbone & Heat Biologics/Univ. of Miami \\
\hline & Molecular clamp stabilized Spike protein & University of Queensland/GSK \\
\hline & S1 or RBD protein & Baylor College of Medicine \\
\hline \multirow[t]{3}{*}{ Replicating Viral Vector } & Measles Vector & $\begin{array}{l}\text { Institute Pasteur/Themis/Univ. } \\
\text { of Pittsburg Center for Vaccine } \\
\text { Research }\end{array}$ \\
\hline & \multicolumn{2}{|l|}{ Horsepox vector expressing } \\
\hline & S-protein & Tonix Pharma/Southern Research \\
\hline \multirow[t]{3}{*}{ RNA } & mRNA & Arcturus/Duke-NUS \\
\hline & saRNA & Imperial College London \\
\hline & mRNA & Curevac \\
\hline VLP & Plant-derived VLP & Medicago Inc. \\
\hline
\end{tabular}


treatment includes the therapies with plasma and antibodies obtained from recuperating patients ${ }^{7,34}$. Further, multiple platforms like DNA and RNA based, recombinant, subunit vaccines could be used for effective vaccine development. The list of different manufacturing platforms and vaccines currently under development for COVID-19 are listed in Table 1.

\section{Perspectives and Conclusion}

Although many viruses are present in their natural host for long time, sometimes due to spill-over event, the virus cross species barrier from animals to humans which can make it more pathogenic and cause devastating outbreak in human population. The outbreak of COVID-19 is the third warning after the outbreaks of SARS and MERS, which depicts the unpreparedness of human community even after more than a decade of coronavirus research. With no vaccine or approved prophylactics to prevent SARS-CoV-2 infection, the virus has spread rapidly to more than 100 countries with high mortality rates and almost all the affected countries are struggling to prevent the virus spread emphasizing its role as serious ongoing human health threat. An effective treatment and preventive measures are urgently required. The detailed action plan along with effective diagnostic and preventive measures could potentially contain the virus spread and eventually reduce the human losses. Although research groups in several countries are working continuously to develop novel therapeutic strategies, repurposing drugs can also be option to consider for treating COVID-19. In addition, development of vaccines for SARS-CoV-2 is highly needed to prevent its outbreak in future. Furthermore, little is known about the pathogenesis and transmission cycles of SARS-CoV-2, hence future work should focus on the elucidation of virus transmission dynamics, and pathophysiology. Development of effective affordable treatment strategies for human coronaviruses could warrant the prevention and control of another emerging human coronavirus similar like SARS-CoV-2 in the future.

\section{ACKNOWLEDGMENTS}

The authors are very thankful to The Department of Biotechnology, Bharathiar University, Coimbatore, Tamil Nadu, India for supporting this research through DST-FIST, UGCSAP and UGC-UKIERI.

\section{CONFLICT OF INTEREST}

The authors declare that there is no conflict of interest.

\section{AUTHORS' CONTRIBUTION}

SR supervised and critically reviewed the manuscript. AM and BS carried out the literature search, drafted the final version and contributed equally to this manuscript. All the authors read and approved the final manuscript.

\section{FUNDING}

None.

\section{ETHICS STATEMENT}

This article does not contain any studies with human participants or animals performed by any of the authors.

\section{DATA AVAILABILITY \\ Not applicable.}

\section{REFERENCES}

1. Shanmugaraj B, Malla A, Ramalingam S. Epidemiology, clinical features and transmission of re-emerging arboviral infection Chikungunya. Asian Pac J Trop Biomed. 2019;9(4):135-139. https://doi. org/10.4103/2221-1691.256726

2. Malla A, Shanmugaraj B, Ramalingam S. Emerging mosquito-borne arboviral infection Zika - An epidemiological review. Asian Pac J Trop Biomed. 2020;10(5):193-200. https://doi.org/10.4103/22211691.281139

3. World Health Organization. Novel Coronavirus (2019nCoV) Situation Report-19. 2020. https://www.who. int/docs/default-source/coronaviruse/situationreports/20200208sitrep-19-ncov.pdf [ Accessed 17 April, 2020]

4. Zirkel F, Kurth A, Quan PL, et al. An insect nidovirus emerging from a primary tropical rainforest. mBio. 2011;2:e00077-11. https://doi.org/10.1128/ mBio.00077-11

5. Gorbalenya AE, Enjuanes L, Ziebuhr J, Snijder EJ. Nidovirales: evolving the largest RNA virus genome. Virus Res. 2006;117:17-37. https://doi.org/10.1016/j. virusres.2006.01.017

6. Cui J, Li F, Shi ZL. Origin and evolution of pathogenic coronaviruses. Nat Rev Microbiol. 2019;17:181-92. https://doi.org/10.1038/s41579-018-0118-9

7. Chen, $Y$, Liu, Q, Guo, D. Emerging coronaviruses: Genome structure, replication, and pathogenesis. J Med Virol. 2020;92:418-423. https://doi.org/10.1002/ 


\section{jmv.25681}

8. Lissenberg A, Vrolijk MM, van Vliet AL, et al. Luxury at a cost? Recombinant mouse hepatitis viruses expressing the accessory hemagglutinin esterase protein display reduced fitness in vitro. J Virol. 2005;79:15054-63. https://doi.org/10.1128/JVI.79.24.15054-15063.2005

9. Fehr AR, Perlman S. Coronaviruses: An overview of their replication and pathogenesis, 2015;1282:1-23. In Maier H, Bickerton E, Britton P. (eds.), Coronaviruses. Methods in Molecular Biology, Humana Press, New York, N.Y. https://doi.org/10.1007/978-1-4939-24387_1

10. Graham RL, Baric RS. Recombination, reservoirs, and the modular spike: mechanisms of coronavirus crossspecies transmission. J Virol. 2010;84:3134-46. https:// doi.org/10.1128/JVI.01394-09

11. Chinese SMEC. Molecular evolution of the SARS coronavirus during the course of the SARS epidemic in China. Science. 2004;303:1666-1669. https://doi. org/10.1126/science.1092002

12. Lewicki DN, Gallagher TM. Quaternary structure of coronavirus spikes in complex with carcinoembryonic antigen-related cell adhesion molecule cellular receptors. J Biol Chem. 2002;277:19727-34. https:// doi.org/10.1074/jbc.M201837200

13. Li F. Structure, Function, and Evolution of Coronavirus Spike Proteins. Annu Rev Virol. 2016;3:237-61. https:// doi.org/10.1146/annurev-virology-110615-042301

14. Wissink EHJ, Kroese MV, Maneschijn-Bonsing JG, et al. Significance of the oligosaccharides of the porcine reproductive and respiratory syndrome virus glycoproteins GP2a and GP5 for infectious virus production. J Gen Virol. 2004;85:3715-23. https://doi. org/10.1099/vir.0.80402-0

15. Narayanan K, Makino S. Characterization of nucleocapsid-M protein interaction in murine coronavirus. Adv Exp Med Biol. 2001;494:577-82. https://doi.org/10.1007/978-1-4615-1325-4_85

16. Ortego J, Ceriani JE, Patino C, Plana J, Enjuanes L. Absence of $E$ protein arrests transmissible gastroenteritis coronavirus maturation in the secretory pathway. Virology. 2007;368:296-308. https://doi. org/10.1016/j.virol.2007.05.032

17. Wilson L, McKinlay C, Gage P, Ewart G. SARS coronavirus $E$ protein forms cation-selective ion channels. Virology. 2004;330:322-31. https://doi. org/10.1016/j.virol.2004.09.033

18. Perlman S, Netland J. Coronaviruses post-SARS: update on replication and pathogenesis. Nat Rev Microbiol. 2009;7:439-50. https://doi.org/10.1038/nrmicro2147

19. Zuniga S, Cruz JL, Sola I, Mateos-Gomez PA, Palacio L, Enjuanes L. Coronavirus nucleocapsid protein facilitates template switching and is required for efficient transcription. J Virol. 2010;84(4):2169-2175. https://doi.org/10.1128/JVI.02011-09

20. Zhou P, Yang XL, Wang XG, et al. A pneumonia outbreak associated with a new coronavirus of probable bat origin. Nature. 2020;579(7798):270-273. https://doi. org/10.1038/s41586-020-2012-7

21. Sola I, Almazan F, Zuniga S, Enjuanes L. Continuous and discontinuous RNA synthesis in coronaviruses. Annu Rev Virol. 2015;2(1):265-288. https://doi. org/10.1146/annurev-virology-100114-055218

22. Masters PS. The molecular biology of coronaviruses. Adv Virus Res. 2006;66:193-292. https://doi. org/10.1016/S0065-3527(06)66005-3

23. $\operatorname{Lim} Y X, N g$ YL, Tam JP, Liu DX. Human coronaviruses: A review of virus-host interactions. Diseases. 2016;4(3):E26. https://doi.org/10.3390/ diseases 4030026

24. Hussain $S$, Pan J, Chen $Y$, Yang $Y, X u J$, Peng $Y$, et al. Identification of novel subgenomic RNAs and noncanonical transcription initiation signals of severe acute respiratory syndrome coronavirus. J Virol. 2005;79(9):5288-5295. https://doi.org/10.1128/ JVI.79.9.5288-5295.2005

25. Li Q, Guan X, Wu P, et al. Early transmission dynamics in Wuhan, China, of novel coronavirus-infected pneumonia. NEng/J Med. 2020;382:1199-207. https:// doi.org/10.1056/NEJMoa2001316

26. Sun J, He WT, Wang L, et al. COVID-19: Epidemiology, Evolution, and Cross-Disciplinary Perspectives. Trends Mol Med. 2020; https://doi.org/10.1016/j. molmed.2020.02.008 [ Accessed 17 April, 2020]

27. Chan-Yeung M, Xu RH. SARS: epidemiology. Respirology, 2003;8(Suppl):S9-14. https://doi.org/10.1046/j.14401843.2003.00518.x

28. World Health Organization. WHO MERS Global Summary and Assessment of Risk. 2018. https:// www.who.int/csr/disease/coronavirus_infections/ risk-assessment-august2018.pdf [Accessed 5 April, 2020]

29. World Health Organization. Coronavirus disease 2019 (COVID-19) Situation Report - 103. 2020. https:// www.who.int/docs/default-source/coronaviruse/ situation-reports/20200502-covid-19-sitrep-103. pdf?sfvrsn=d95e76d8_4 [ Accessed 3 May, 2020]

30. Huang $C$, Wang $Y, L i X$, et al. Clinical features of patients infected with 2019 novel coronavirus in Wuhan, China. Lancet. 2020;395:469-470. https:// doi.org/10.1016/S0140-6736(20)30183-5

31. Shanmugaraj B, Malla A, Phoolcharoen W. Emergence of Novel Coronavirus 2019-nCoV: Need for rapid vaccine and biologics development. Pathogens. 2020;9:148. https://doi.org/10.3390/pathogens9020148

32. Frieden TR, Lee CT. Identifying and interrupting superspreading events-implications for control of severe acute respiratory syndrome coronavirus 2. Emerg Infect Dis. 2020. Accessed 17 April, 2020. https://doi.org/10.3201/eid2606.200495

33. Centers for Disease Control and Prevention. Coronavirus Factsheet. 2019. https://www.cdc.gov/ coronavirus/2019-ncov/about/transmission.html, Accessed 16 April 2020.

34. Shanmugaraj B, Siriwattananon K, Wangkanont K, Phoolcharoen W. Perspectives on monoclonal antibody therapy as potential therapeutic intervention for Coronavirus disease-19 (COVID-19). Asian Pac J Allergy Immunol. 2020;38(1):10-18.

35. WHO. Draft landscape of COVID-19 candidate vaccines. https://www.who.int/blueprint/priority-diseases/ key-action/novel-coronavirus-landscape-ncov.pdf [Accessed 16 April, 2020] 